\title{
Guideline for use of oxytocin for induction and augmentation of labour
}

Oxytocin is an invaluable drug when used carefully. However, it has the potential to cause uterine hyperstimulation, which could result in amniotic fluid embolism, uterine rupture and fetal distress, all of which are life threatening.

Multigravidae are particularly susceptible to the above consequences and extra care must be taken to exclude obstruction before a decision is made to use oxytocin in a multigravid woman during labour. Experienced personnel must be involved in this decision.

Use of oxytocin for induction and/or augmentation of labour results in a higher risk of rupture of a scarred uterus. Therefore, in such women oxytocin should be used only with the concurrence of a Consultant.

Its effects will depend on the concentration of the infusion and the volume infused per minute.

To achieve this predictably, use of infusion pumps is recommended.

Where a gravity-assisted drip system is used, a burette may be used to improve accuracy. Such systems however, may deliver variable volumes depending on many factors including the position of the arm into which it is infused.

Irrespective of the method of administration, oxytocin must be administered in incremental doses at intervals of 30 minutes, to achieve a contraction free interval of two minutes. Once this level is reached, the infusion rate may be continued at the same level, while closely monitoring the contractions.

Hyperstimulation is defined either as a contraction free interval of less than sixty seconds and/or contractions lasting more than ninety seconds. In this situation the infusion must be stopped immediately.

Oxytocin is administered with 5 units in $500 \mathrm{ml}$ of $0.9 \%$ sodium chloride solution. In situations where infusion pumps are not available, oxytocin may be administered starting at a drop rate of 15 per minute and increased at rates of 15 drops per minute every 30 minutes, up to a maximum of 60 drops per minute. An approximate conversion to $\mathrm{mU} /$ minute is given in Table 1 .

Table 2 gives mU infused per minute when administered via an infusion pump.

Oxytocin must not be administered to women with intact membranes. It is recommended that women on oxytocin infusions should have continuous electronic fetal monitoring.

\section{Continuous EFM during administration of oxytocin:}

- If the CTG is normal, oxytocin may be continued in incremental doses until the woman is experiencing 4 or 5 contractions every 10 minutes.

- If the FHR trace is suspicious, this should be reviewed by an experienced medical officer.

- If the FHR trace is classified as abnormal/ pathological oxytocin infusion should be stopped and a full assessment of the fetal condition undertaken by an experienced medical officer.

Table 1. $\mathrm{mU} / \mathrm{minute}$ administered at different rates of administration according to drop rate

\begin{tabular}{cc}
\hline Drop rate/min & Equivalent $\mathrm{mU} / \mathrm{min}$ \\
\hline 15 & 7.5 \\
30 & 15 \\
45 & 22.5 \\
60 & 30 \\
\hline
\end{tabular}

(based on $5 \mathrm{U}$ of oxytocin in $500 \mathrm{ml}$ saline)

Table 2. mU infused per minute when administered via an infusion pump

\begin{tabular}{ccc}
\hline $\begin{array}{c}\text { After starting } \\
\text { (Mins) }\end{array}$ & $\begin{array}{c}\text { Oxytocin dose } \\
(\mathrm{mu} / \mathrm{min})\end{array}$ & $\begin{array}{c}\text { Volume infused } \\
(10 \mathrm{u} \text { in } 500 \mathrm{mls} \\
\mathrm{mls} / \mathrm{hr}) \\
\text { Rate }\end{array}$ \\
\hline 0 & 1 & 3 \\
30 & 2 & 6 \\
60 & 4 & 12 \\
90 & 8 & 24 \\
120 & 12 & 36 \\
150 & 16 & 48 \\
180 & 20 & 60 \\
210 & 24 & 72 \\
240 & 28 & 84 \\
270 & 32 & 96 \\
\hline
\end{tabular}

